\title{
Translation Training Based on Computer and Internet
}

\author{
Guifen, Wang \\ Foreign Language School, Wuhan Institute of Technology, Wuhan, 430205, China \\ email: lindawang58@126.com
}

Keywords: web-based translation teaching; computer- aided translation

\begin{abstract}
According to the problem that the intelligence is not high of the soccer robot, using the mechanical theory as a guide, making some mechanical analyses and calculations on the pressure and transmutation states of chip kick mechanics, and conducting optimal design too, then making the structure of chip kick mechanics more and more rationalization. Experiments show that the new soccer robot controller features a quick response and high servo rigidity, and provide a kind of method for improving and perfecting the soccer robot control system, at the same time, filling the needs of producing.
\end{abstract}

\section{Introduction}

The concept of E-teaching is not new to us anymore no matter how it is defined as "internet-based teaching”, “online-teaching”, "networked-based teaching”, and "web-based teaching”. The computers and multimedia have their unique features which mark the distinction between traditional teaching and E-teaching. By offering immediate interaction between translation learners, as well as between learners and their instructors, the information technology may provide the most fertile ground and efficient platform for target text construction. So in translation teaching and translator training, computers and web-enhanced learning bear enormous value.

Indeed teaching computer-aided translation (CAT) is a way of introducing students to the kind of skills that are of vital importance in the language service industries. In recent years, we are witnessing a great output in a very short time of those translation corporations. Yet such kind of training courses have not been attached due importance to in either the translation or the foreign language education in most universities in the mainland of China. So in the following part the paper reports on the experience of applying a computer-aided translation system into the translation workshop.

\section{Information of the Training}

A. Translation teaching or training setting

The translation training scenario discussed in the paper takes place at Wuhan Institute of Technology, Hubei province, mainland China. Nonetheless, the training experience here exposed could be helpful to other translation training settings, which may often result from an urgent need for updating knowledge and fast developing new translation market skills, e.g. professional development seminars dealing with translation aids, held at university or elsewhere.

\section{B. Students' Profile}

In this particular case, the translation training subjects are 36 final-year Foreign Language school undergraduates majoring in English. Among those 101 English undergraduates these 36 students choose translation as their further developing direction or career direction. They all have limited background in computing and translation technology applications. The teachers are specialized in language teaching and translation who received the training about how to use Computer-Aided Translation (CAT) and Computer Aided Translator Training Platform (CATTP) provided by computer engineers. 


\section{Computer Aided Translator Training Platform}

The translation-training scenario takes place on a CATTP, developed by Transn Information Technology Ltd Corporation in China. The platform integrates translator management, project management, computer-assisted translation tool and instruction assistance features. The platform offers two kinds of training, free individual translation practice and group tasks of mimic real translation projects dealt with in the language industry.

Free Individual Translation Practice

For free individual practice, students can choose a translation task from many different kinds which are categorized by subject matters to be translated. They can also choose the translation direction, i.e. translation into or from mother tongue. Such a practice is web-based. Students can choose any time to get online and tick the system to begin a translation task. Or they can also download the task and do it elsewhere. In this case, they won't have the common resources shared in the system, i.e. the common computer memory and glossaries. When they have finished the task, they just have to submit it in the system.

In individual practice, students interact with the computer in several different ways. They can choose whatever subject matter they are interested. Proper use of computer-aided technology can help them to get quick translation and promote their ability to select better target text. After they submit their own translated version, they can check the version provided by the CATTP and the system can offer certain comparison between the student's version and the referenced one. This is a good way for the student's self training. In the process, students will realize that automation combined with human intervention can produce good work and higher efficiency. Such a sense of control towards technology will benefit them in their future career.

Group project training

In group task of mimic translation project, students choose a role to play from three: project manager, translator, or reviser when they log in the system. This group training follows the workflow of the real project carried out in the large language service enterprises in that each role has to do exactly the same thing as the those who work in the enterprises.

For example, the project manager has to set up a team by inviting translators who are specialized in the subject the project concerns; he has to do much text pre-editing, i.e. breaking the whole work into several parts and distribute them to translators; he also has to estimate the cost of the project and the workload and follow translators' progress to guarantee the project to be finished in time; he is the one who contact with the clients, etc.

In group tasks, students have to interact not only with computers but also with other members of the team through the communication module of the system based on web. Project manager has to interact with translators and revisers. Every translator has to coordinate with other ones in choosing uniform versions of technical terms and sharing expressions so that the target text becomes a coherent and integrated whole. Translation revisers not only guarantee the quality of the final version, but also play a role in the process of translating in correcting and directing the translation.

\section{The training scenario}

The train scenario adopted Kiraly's maxim that "learning to be a professional translator means learning to act as one [1].” The system gives students a sense to deal with CAT as if they were already employing it in their workplace. The training lasted three weeks consisting of two kinds of activities: in-class group work (twice every week) and spare time self-training (at least 5 tasks). In class training, all the 36 students came to the language lab for face-to-face translation instruction and practice. Each time they finished at least one group task set by the teacher. In the group project, students formed groups and chose roles by themselves but each student should experience all the three roles in three weeks' time, i.e. every student played the role of project manager, translator and reviser at least one time. This arrangement sees to it that students get familiar with all the procedures of the real project workflow and get the teacher's immediate face to face guide when difficulty arise concerning both how to use the system or how to do translation.

The main goal here would be to collaborate (i.e. share and apply knowledge) in translation 
projects involving Internet-based application of CAT systems. The students would not only learn about the system's features but would also develop new translation skills and linguistic skills (e.g. preparation or text pre-editing, post-editing, computer memory expansion, glossaries updating).

\section{Training Feedback And Future Prospect}

\section{Students' performance}

Computers have been used for language learning and teaching in the west countries since the 1960s. They promote students' active engagement in the learning process and changed the teacher' role. Similar effect was found in this internet-based translator training scenario.

At beginning of the training, students didn't show much suspicion about the great role computers play in translation industry. They seemed to be quite willing to apply CAT technology into use. That is quite different from what Elia Yuste Rodrigo described 10 years ago [2]. In his teaching experiences, learners showed fear of and prejudge against machine translation. This is partly because of the fact that computers are recognized to be widely used in the field. Another important reason is that younger generations are more ready to accept electronic technology. Of course, the training focused more on CAT instead of Machine Translation. That also accounted for the difference in learners' responses.

During the three weeks' in-class training, students appeared to be much more engaged than in their usual classes. They were found to be interacting much more with one another in exploring the system or selecting the proper target expressions. And they interacted with their teacher more often than in traditional classes where the teacher stands on the platform presenting the knowledge. Besides enhanced engagement, students' responsibility and prospect-reader awareness were naturally increased too, because the on-line system makes it possible for the teacher (or the reviser) to see the translator's translation process. The teacher can offer immediate feedback and guide to the student's target text production in the on-line system, which produces the effect as Chen Ling described [3]: "Translators produce their target text as if an artist painted on a transparent glass. The others around can see the work clearly.” The teacher's participation in the students' translating process greatly improves teacher-student- interaction in that the teacher's feedback becomes more "immediate, fair and constructive" rather than error-picking, frustrating and conclusive that tends to be in the traditional way of translation evaluation of students' final work[4].

As to the free individual self-training, all the students finished at least five self-training translation tasks before the deadline. The language lab (usually open to students for self-learning) administrator reported the number of students coming for self-learning increased noticeably during that period of time.

The target texts students submitted were found to be done with more care since there were little silly errors, which might be resulted from their increased sense of responsibility and prospect-reader-awareness that a professional translator should have.

The Teacher's Role

In this web-based translation training, the teacher's role changed dramatically from traditional one, in which teachers became the translation activity designers, organizers and sometimes the counselors, facilitators when difficulty occurred in the application of CAT, instead of the knowledge presenter. Still teachers would be assessors in choosing proper target language expressions. Thus in the training process, the role of teacher changed for the need of learning. This student-centered translation training views learners as active meaning constructors. "In other words, based on their prior experience, students actively construct their knowledge through active participation in problem-solving and critical thinking.[5]” The teacher facilitates this constructive process.

Future Prospect

In the training both teachers and students were discouraged by two aspects of the system: rigidness of the system and the mimic nature of the translation projects.

The module-supported system has its limitations. The greatest inconvenience is that many functions will only be realized on the local network. For example, many resources, like translation memory, glossaries, have to be shared, expanded or built in the language lab on the school network. 
If students have to apply CAT, they have to come to the language lab to do it. This makes some web-based functions inaccessible. Another low point is that interactive form is remarkably fixed. The system won't support the multi-translators' participation in the same text translation. And interaction among students (or translators), student-teacher (or translator-reviser) interaction are very much inflexible. These undermine students' participation in the interaction. Still more, system update is another question.

Besides the technical limitation, students also expressed the wishes to do the real translation project provided by enterprises. The mimic ones seem a little boring since they lack the real clients, thus losing the total sense of reality.

Considering some of the above drawbacks, the paper here prospects a Cloud-based service to be developed in CATTP. Cloud service makes the system easier to be used on the internet in that the translation corpus can be collected, thus the system resources can be expanded or retrieved on the internet. Both students and teachers can apply CAT without the restraint of time and space. Secondly it makes the university-enterprises collaboration possible in offering real projects services. It is a win-win arrangement in that students get a chance to undertake real projects and the enterprise can get relatively cheaper services.

\section{Conclusion}

The application of CATTP in college translation teaching definitely plays a positive role. It is highly proposed here to incorporate it into foreign language education curriculum, more particularly to translation syllabus, as a compulsory course. It is also expected that the system improved to Thanks to the system, our students changed from naively ignorant to welcoming standpoint as regards to information technology in translation. This also helped them to act more confidently and resourcefully in their future assignments as translators.

\section{Acknowledgement}

In the paper, the translation teaching mode research is supported by Education Planning Project of Hubei Province (granted No 2010B102).

\section{References}

[1] D. Kiraly, "From teacher-centered to learning-centered classrooms in translator education: control, chaos or collaboration?” In Innovation in Translator and Interpreting Training (ITIT) - An on-line symposium (17--25 January 2000).

[2] E. Y. Rodrigo, "Making MT commonplace in translation training curricula: too many misconceptions, so much potential!." MT Summit VIII. CD-ROM Proceedings of the 8th International Machine Translation Summit--'Machine Translation in the Information Age.' Santiago de Compostela (Spain), 18th-22nd September (2001): pp45-49.

[3] L. Chen, "To Create New Mode Of Translation Teaching through Multimedia Classroom Interaction,” China Educational Technology, vol.251, 2007(12): 90-92,

[4] L. R. Zeng, W. Q. Xiao, and L. L. Yan, "Cloud--based University-enterprise Collaborative Translation Instruction and Production Platform," Shanghai Journal of Translators, 2012(4): 46-50

[5] Zhiyi Fu, “On the Applications of Modern Educational Technology in Translation Teaching of Maritime English from the Perspective of Constructivism” Journal of Language Teaching and Research, Vol. 1, No. 4, pp. 412-415, July 2010 Academy Publisher manufactured in Finland. doi:10.4304/jltr.1.4.412-415. 